Journal of English Language Teaching and Applied Linguistics

ISSN: 2707-756X

DOI: $10.32996 /$ jeltal

Journal Homepage: www.al-kindipublisher.com/index.php/jeltal

\title{
Effectiveness of English -Speaking Foreign Teachers from the Learners' Perspective at Ho Chi Minh University of Food Industry
}

\author{
Nguyen Giang Huong 8 \\ Faculty of Foreign Languages, Ho Chi Minh City University of Food Industry, Vietnam \\ $\square$ Corresponding Author: Nguyen Giang Huong, E-mail: huongng@hufi.edu.vn
}

\section{ARTICLE INFORMATION}

Received: May 08, 2021

Accepted: June 02, 2021

Volume: 3

Issue: 6

DOI: 10.32996/jeltal.2021.3.6.14

\section{KEYWORDS}

Effectiveness of foreign teacher, favor with English, minimize disadvantages, motivate student

\section{ABSTRACT}

Ho Chi Minh University of Food Industry (HUFI) is gradually reforming and updating English teaching methods to enhance the learners' quality. Within this context, foreign teachers are required to teach in English speaking classes with the assistance and observation of native teachers. This study developed factors that foreign teacher influencing the learner's favour with English. An online google form questionnaire was conducted on participants called students at HUFI. The respondents answer an openended questionnaire. The results will benefit English-speaking-foreign teachers (ESFTs) in terms of realizing their strengths and weaknesses. This study aimed to develop solutions to minimize disadvantageous factors and maximize benefits to motivate students toward learning English in classes with foreign teachers.

\section{Introduction}

HUFI is attempting to innovate teaching methods to help learners conquer knowledge through the development period. As a result, HUFI has made many changes from renewing premises, equipping teaching tools to make teaching more effective. Implementing this policy, the HUFI Faculty of Foreign Language is finding solutions to improve and enhance learning and teaching English. One of the solutions applied, for example, is setting English-speaking-foreign teachers (ESFTs) side by side with local English teachers. These foreign teachers with qualifications are recruited from different nationalities like the Philippines, Canada, Netherlands and Ireland.

In her research, Florence (2012) said a teacher having linguistic competence in a language does not automatically mean he or she is a good teacher because language possession is quite different from language teaching and transmission. In other words, although these language teachers speak English natively or as their second language in their countries, not all of them may be good at teaching so that students can understand and love English learning.

Recent studies regarded three main factors affecting teaching effectiveness: knowledge of English major, pedagogical skills, and characteristics. However, this article examines the effectiveness of setting up English-speaking- foreign teachers in classrooms at HUFI in terms of two aspects through students' views. These are teacher's pedagogical skills and characteristics. Based on the evidence above that they have spoken English as a native or second language, the paper will not refer to knowledge of English major.

This assessment is also important to find out what works and does not work when teachers improve teaching effectiveness. Student's comments, preference and observations on teaching styles and the quality of foreign teachers are valuable for teaching directions at HUFI.

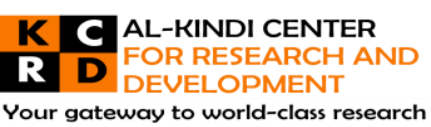

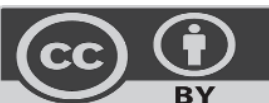

BY
Published by Al-Kindi Center for Research and Development, United Kingdom. Copyright (c) the author(s). This open access article is distributed under a Creative Commons Attribution (CC-BY) 4.0 license 


\section{Literature Review}

\subsection{An effective teacher}

So far, there have been so many definitions of an effective teacher, and different authors may give different explanations for that. It's really a complex task. Walker (2008) described an effective teacher as a person that can help learners in the most successful ways. He mentioned twelve characteristics that create an effective teacher listed as prepared, positive, hold high expectations, creative, fair, display a personal touch, cultivate a sense of belonging, compassionate, have a sense of humor, respect student, forgive, and admit mistakes.

In a similar agreement given by Stronge (2018), a portrait of an effective teacher is not just assessed toward skills or dispositions, but the whole person in terms of learners beliefs, values, attitudes, aspirations, motivation, knowledge, and skills. In other words, he highlighted qualities and characteristics of effective teachers from many perspectives, including professional knowledge, instructional planning, instructional delivery, assessment, learning environment, and professionalism.

While Clark \& Walsh (2002) demonstrated some features that a successful teacher should have like strong discipline content knowledge; pedagogical skills appropriate to the environment and discipline; personal knowledge, which included: the ability to forge a strong relationship with the students, a concern for individual students and a firm moral code; and intimate knowledge of the context in which they were teaching. Then Sammons \& Bakkum (2013) reviewed that a teacher who can finish teaching goals and tasks that they set up is called an effective teacher. Besides, this effectiveness is calculated through student's progress and outcomes. In terms of Cheung's viewpoint (2006), enthusiasm for teaching and corresponding with students is a factor of an effective teacher.

With regards to an effective teacher, Astor (2000) explains that first, he must be a qualified teacher of English who is professional in at least three aspects of knowledge: « pedagogy, methodology, and psycho and applied linguistics ». He adds that lacking one of these areas is impossible to make a teaching and learning environment achieve its goals.

Arikan, Tacer \& Sarac Suzer (2008) found in Cheung's study (2006, pp. 435-436) that effective teachers inclined towards :

« Remain in their posts for longer periods of time,

- Spend more time on teaching and curricular planning,

- Be enthusiastic about teaching,

- Be sensitive towards their students' needs,

- Tolerant towards their students' mistakes and errors,

- Work with problem students for longer periods of time,

- Participate and build onto the learning experiences of their students ».

\subsection{Pros and Disadvantages of ESFTs}

Many studies on the advantages of English-speaking-foreign teachers (ESFTs) have been conducted. One of the advantages that an English-speaker foreign teacher brings to the classroom is creating a real English communication environment where learners and teachers can exchange ideas in real English. In one finding from Florence (2012), students said that ESFTs assist their English learning more easily and effectively because they have a chance to practise English with teachers who speak English as a mother tongue or a second language. In that case, an authentic English-speaking environment was created in classrooms, and students had no alternatives. They have to speak English to make sense of everything and to be understood. Then, Florence concluded that the more English was used, the more effective and efficient learning was achieved. In a study by Benke \& Medgyes (2005), native -English speaking teachers are appreciated because of their advantages, among which, one of them is the fact that they are very well capable of teaching conversation classes and serving perfect models for imitation. They have a various amount of vocabulary on social life, cultures and academy. Additionally, the study found that many students prefered studying English with foreigners, especially pronunciation, speaking, and culture.

On the other hand, some disadvantages of an English-speaking foreign teacher were revealed. Students' perceptions in a study by Benke and Medgyes (2005) showed that foreign teachers are usually hard to understand, especially at lower levels where their grammar and vocabulary are not varied. Walkinshaw \& Oanh (2014) founded from Mahboob's (2003) study that Englishspeaking foreign teachers often had a little facility with grammar and had difficulty explaining complicated items because they neither experience learning intense grammar as foreign language learners nor have appropriate teaching methods in different contexts or with ages.

\subsection{Pedagogy}

As mentioned above, an effective teacher cannot lack professionalism in teaching and pedagogy describes the teaching strategies used within the classroom (Bhowmik, Banerjee, \& Banerjee, 2013, p. 1). 
In terms of pedagogy, two aspects should be mentioned: pedagogical knowledge and pedagogical skill « Pedagogical knowledge is knowledge for teaching. It involves knowledge of how to teach content as a condition for teacher effectiveness. Pedagogical knowledge and skill deal with instructional techniques and strategies which enable learning to take place.» (Amosun \& Kolawole, 2015). No one can deny the importance of displaying pedagogical knowledge and skills in a teaching career. It helps teachers think about the best possible methods, strategies, materials, and resources to be utilized for the learning situation; it helps teachers know how to utilize various forms of play, different strategies for grouping learners; different types of media and materials. Pedagogical knowledge and skills turn teachers into facilitators, coaches, models, evaluators, managers, and advocates. It helps teachers employ appropriate evaluation schemes. Effective pedagogy helps teachers display skills at creating curricula designed to build on learners' present knowledge and understanding and move those learners to more sophisticated and in-depth abilities, knowledge, concepts, and performances. Thus, effective teaching requires pedagogical skills so that the teaching is carried out smoothly and results in the maximum output in terms of the expected teaching outcomes.

\section{Methodology}

This paper aims to analyze the students' satisfaction with English-speaking foreign teachers. The strengths and weaknesses can be defined. For that reason, a descriptive research method is used. This part lists the methodology used in this research: the study subjects, the instrument and the procedure for data collection. It also points out the study's limitations.

\subsection{Subjects of the study}

Participants are 200 learners of English major at Ho Chi Minh University of Food Industry, aged from 20 to 22 . They are 160 female and 40 male students. They have had 3 or 4 years studying English major here and indifferent backgrounds from rather fair, average to excellent students. These English-major learners were chosen because they have experienced a lot of time learning and practise speaking with English-speaking foreign teachers, about $50 \%$ during the course time.

\subsection{Data Collection Instrument}

The instrument for data collection was questionnaires in English without names of learners showing students' perceptions toward studying English with English-speaking foreign teachers. The study follows some characteristics that make up an effective teacher in Walker's research (2008): be prepared, be positive, and hold high expectations, which referred to building students' confidence and teaching them to believe in themselves. Moreover, some more assessments were set up to make the focus clearer.

The student participants were asked questionnaires in relation to their perceptions of English-speaking-foreign teachers' pedagogical skills as well as results they have got from this studying practice where they were required to tick the appropriate category. The design employed four-point rating scale questions, from 4=strongly agree to $1=$ strongly disagree.

These are the questionnaires:

Students' perceptions of foreign teachers :

1. The English-speaking-foreign teachers (ESFTs) prepare lesson well.

2. The English-speaking-foreign teachers (ESFTs) use technology to motivate students.

3. The English-speaking-foreign teachers (ESFTs) make students feel relaxed and ready to study.

4. The English-speaking-foreign teachers (ESFTs) make learners discover a new language.

5. The English-speaking-foreign teachers (ESFTs) manage the classroom effectively.

Students's self-assessments :

1. Do you feel confident speaking with foreign teachers?

2. Do you think that your English is improved when studying with foreign teachers?

3. Will you recommend having English-speaking foreign teachers (ESFTs) in your next courses?

\subsection{Data collection procedure}

Students who took part in the study were introduced to the research purpose and procedure. Then each of them was delivered a piece of paper with questionnaires requiring them to tick on the agreed rate. After about 10 minutes, all papers were collected.

\section{Results and Discussion}

Table 1 : Students' perceptions on foreign teachers

\begin{tabular}{|c|c|c|c|c|}
\hline Items & Strongly agree & Agree & Disagree & Strongly disagree \\
\hline $\begin{array}{l}\text { 1. The English-speaking-foreign } \\
\text { teachers (ESFTs) prepare lesson }\end{array}$ & $\begin{array}{l}110 \\
55 \%\end{array}$ & $\begin{array}{c}80 \\
40 \%\end{array}$ & $\begin{array}{l}10 s t \\
5 \%\end{array}$ & $\begin{array}{c}0 \\
0 \%\end{array}$ \\
\hline
\end{tabular}




\begin{tabular}{|c|c|c|c|c|}
\hline well. & & & & \\
\hline $\begin{array}{l}\text { 2. The English-speaking-foreign } \\
\text { teachers (ESFTs) use technology } \\
\text { to motivate students. }\end{array}$ & $\begin{array}{c}73 \\
36.5 \%\end{array}$ & $\begin{array}{l}120 \\
60 \%\end{array}$ & $\begin{array}{c}7 \\
3.5 \%\end{array}$ & $\begin{array}{c}0 \\
0 \%\end{array}$ \\
\hline $\begin{array}{l}\text { 3. The English-speaking-foreign } \\
\text { teachers (ESFTs) make students } \\
\text { feel relaxed and ready to study. }\end{array}$ & $\begin{array}{c}31 \\
15.5 \%\end{array}$ & $\begin{array}{c}44 \\
22 \%\end{array}$ & $\begin{array}{c}92 \\
46 \%\end{array}$ & $\begin{array}{c}33 \\
16.5 \%\end{array}$ \\
\hline $\begin{array}{l}\text { 4. The English-speaking-foreign } \\
\text { teachers (ESFTs) make learners } \\
\text { discover new language. }\end{array}$ & $\begin{array}{c}88 \\
44 \%\end{array}$ & $\begin{array}{c}82 \\
41 \%\end{array}$ & $\begin{array}{c}25 \\
12.5\end{array}$ & $\begin{array}{c}5 \\
2.5 \%\end{array}$ \\
\hline $\begin{array}{l}\text { 5. The English-speaking-foreign } \\
\text { teachers (ESFTs) manage } \\
\text { classroom effectively. }\end{array}$ & $\begin{array}{c}67 \\
33.5 \%\end{array}$ & $\begin{array}{c}106 \\
53 \%\end{array}$ & $\begin{array}{c}19 \\
9.5 \%\end{array}$ & $\begin{array}{c}8 \\
4 \%\end{array}$ \\
\hline
\end{tabular}

The results in Tables 1 and 2 are demonstrated with the number of students and are calculated in percentages. In general, students have a good perception of foreign teachers because the percentage is shown in «strongly agree» and «agree» is higher than that in « disagree » and « strongly disagree » columns.

In table 1 , in terms of lesson preparation and planning of foreign teachers, a total of $55 \%$ of respondents strongly agreed that teachers do well in this task. This is even higher than the percentage that student vote in the « agree » column. Lehmann (2001) addressed that lesson planning is really important and it is one of the crucial factors to become an effective teacher. It is amazing that no participants ticked into « strongly disagree ». This result indicated that foreign teachers are highly aware of the formality in the teaching career and the importance of preparation. This feature is appreciated by students when there were not any votes for «strongly disagree » in item 2, which is about teachers' using technology and motivation. This means that foreign teachers also pay much attention to investing in contents as well as the teaching methods to help students study well.

Using technology in teaching and learning creates interesting images and games which make the lessons more vivid and easy to be acquired.

With item 3, there were $46 \%$ did not agree that the English-speaking-foreign teachers (ESFTs) make students feel relaxed and ready to study. Significantly, the percentage of strongly disagree was $16.5 \%$. This result was assumed to come from relatively fair or average students who usually feel nervous whenever be called to speak. In addition, some foreign teachers are strict and set up difficult tasks which make students feel scared. Anyways, these students agreed that the English-speaking-foreign teachers (ESFTs) make learners discover new language as the percentage in the strongly disagree column went down and be highest in strongly agree.

In item 5, 53\% agreed that the English-speaking-foreign teachers (ESFTs) effectively managed a classroom while 9.5\% and 4.0\% did not agree. A small number of students did not think that foreign teachers managed the classroom well because they focus on students speaking or giving presentations, not on the rest of the students. Then the rest could make noise or do their tasks. As a result, it is really necessary to have pedagogical skills so that an effective teacher can manage a class.

In sum, the overall results in table 1 showed that most students agreed with the given criteria in the assessment procedure of foreign teachers and also, these are advantages that foreign teachers possess that are more dominant than their disadvantages.

Table 2: students's self-assessments

\begin{tabular}{|l|c|c|c|c|}
\hline \multicolumn{1}{|c|}{ Items } & Strongly agree & Agree & Disagree & Strongly disagree \\
\hline $\begin{array}{l}\text { 1. You feel confident to } \\
\text { speak with foreign } \\
\text { teachers? }\end{array}$ & $\begin{array}{c}69.5 \% \\
\text { You think that your }\end{array}$ & $\begin{array}{c}93 \\
46.5 \%\end{array}$ & $\begin{array}{c}14.5 \% \\
9.5 \%\end{array}$ \\
\hline $\begin{array}{l}\text { 2. Ynglish is improved when } \\
\text { studying with foreign }\end{array}$ & $41 \%$ & $50 \%$ & $18 \%$ & 0 \\
\hline
\end{tabular}




\begin{tabular}{|l|c|c|c|c|}
\hline teachers? & & & & \\
\hline 3. You will recommend & 57 & 97 & 34 & $12 \%$ \\
having English-speaking- \\
foreign teachers (ESFTs) in \\
your next courses?
\end{tabular}

The results in table 2, which is students's self-assessments, seemed perspective. Although in item 1 there were $14.5 \%$ students disagreed that they felt confident to speak with foreign teachers, at last, this percentage in the same column reduced when $12 \%$ did not want to have foreign teachers in their classrooms. This number also showed that students still want to be taught English by foreign teachers although sometimes they felt worried and nervous when asked to answer questions. One more reason for that is that students thought their English improved, at least in pronunciation, intonations, and knowledge of cultures.

\section{Conclusion and suggestions}

This paper aims to discover the advantages and disadvantages of English-speaking-foreign teachers (ESFTs) since then, develop solutions to minimize disadvantageous factors and maximize benefits to motivate students toward learning English in classes with foreign teachers. Still, there are some limitations in the research. Because this is just a small-scale study, the result is not as satisfactory as the author wished. Furthermore, these are just a few questionnaires, and then they may not cover all the aspects of making an effective teacher. Therefore, in the next study, more questions and various kinds of questionnaires should be applied. Although of these shortages, suggestions are also given as follows:

First, from the findings, one major conclusion that could be taken out is English-speaking-foreign teachers (ESFTs) are doing well on their job. As a result, the direction of the board of HUFI in using foreign teachers is moving positively and appropriately in the 21-century learning environment. Besides local English teachers, more and more foreign teachers need to be approached by students to help learners open their minds to knowledge and an English-speaking environment.

Second, there should be some improvements on foreign teachers' pedagogical skills, such as watching all students in the classroom as a whole to draw their attention to the lesson. Also, to reduce nervousness or intension from students, foreign teachers need to have a positive feeling and helpful attitude at the beginning of the lesson. English-major subjects are not always easy for students to understand and access, so teachers should start from easy to difficult questions and have warm-up questions when making questions.

Finally, there should be more social activities with the participation of foreign teachers and students. In this way, they can learn about other's cultures and exchange information related to the major. This is also a way to help students be interested and love English due to friendly teachers.

Funding: This research received no external funding.

\section{Acknowledgements:}

First of all, I would like to thank the students who participated in the questionnaires, then the teachers in the Faculty of Foreign Language, University of Food Industry, Ho Chi Minh (HUFI), provided me with the knowledge to successfully complete the study. I also would like to thank the Board of Foreign Language Faculty of HUFI for encouraging me to the end. I would like to wish you all good health, success in work and life. Thank you sincerely. The author, however, bears full responsibility for the paper.

Conflicts of Interest: The authors declare no conflict of interest.

\section{References}

[1] Arikan, A., Taşer, D., \& Saraç-Süzer, H. S. (2008). The effective english language teacher from the perspectives of turkish preparatory school students. Egitim ve Bilim, 33(150), 42-51.

[2] Amosun, M. D \& Kolawole, O.A. (2015). Pedagogical Knowledge and Skill Competences of Pre-school Teachers in Ibadan Metropolis, Oyo State, Nigeria.

[3] Astor, A. (2000). A qualified nonnative English-speaking teacher is second to none in the field. TESOL Matters, 10(2), 18-19.

[4] Amusan, M. (2016). Cultivating Effective Pedagogical Skills in In-Service Teachers: The Role of Some Teacher Variables. Journal of the International Society for Teacher Education, 20(1), 83-89.

[5] Cheung, H. Y. (2006). The measurement of teacher efficacy: Hong Kong primary in-service teachers. Journal of Education for Teaching, 32(4), 435-451.

[6] Florence Ma, L. P. (2012). Advantages and Disadvantages of Native- and Nonnative-English-speaking Teachers: Student Perceptions in Hong Kong. TESOL Quarterly, 46(2), 280-305. https://doi.org/10.1002/tesq.21

[7] Guerriero, S. (2014). Teachers' Pedagogical Knowledge and the Teaching Profession. From www.oecd.org. Stronger, J. (2018). Qualities of effective teachers. 
[8] Moussu, L. M. (2006). Native and Nonnative English Speaking English As A Second Language Teacher: Student Attitudes, Teacher SelfPerceptions, and Intensive English Administrator Beliefs and Practices. Purdue University.

[9] Stronge.J. (2018). Effective teaching:what does it all mean? In Qualities of effective teachers.

[10] Sundari, H. (2018). The Qualities of an Effective English teacher: University students' perception. Asian EFL Journal, 20(5).

[11] Walker, R. (2008). Twelve Characteristics of an Effective Teacher: A Longitudinal, Qualitative, Quasi-Research Study of In-Service and PreService Teachers' Opinions. Educational Horizons, v87, p61-68. http://www.eric.ed.gov/ERICWebPortal/recordDetail?accno=EJ815372

[12] Walkinshaw, I., \& Oanh, D.H. (2014). Native and Non-Native English Language Teachers: Student Perceptions in Vietnam and Japan. SAGE Open. https://doi.org/10.1177/2158244014534451.

[13] Wardak, M. (2014). Native and Non-Native English Speaking Teachers' Advantages and Disadvantages. Arab World English Journal 5(3),124141. 